\title{
Comparison of Lipid Peroxidation and Anti-Oxidant Activities in Pre-Eclamptic \& Normal Pregnancies in Nigerian Population
}

\author{
Adetunji O. Adeniji ${ }^{1 \#}$, Dolapo P. Oparinde ${ }^{2}$ \\ ${ }^{1}$ Department of Obstetrics \& Gynaecology, College of Health Sciences, Ladoke Akintola University of Technology, Ogbomoso, \\ Nigeria; ${ }^{2}$ Department of Chemical Pathology, College of Health Sciences, Ladoke Akintola University of Technology, Ogbomoso, \\ Nigeria. \\ Email: "tunji1802@yahoo.com
}

Received February $23^{\text {rd }}, 2013$; revised March $28^{\text {th }}, 2013$; accepted April 20 $0^{\text {th }}, 2013$

Copyright (C) 2013 Adetunji O. Adeniji, Dolapo P. Oparinde. This is an open access article distributed under the Creative Commons Attribution License, which permits unrestricted use, distribution, and reproduction in any medium, provided the original work is properly cited.

\begin{abstract}
Purpose: To compare the serum malondialdehyde (MDA) and total antioxidant status in women with preeclampsia and normal pregnancy in our environment. Materials \& Methods: This was a 3-year, cross-sectional, case control study of 100 preeclamptic and 200 normotensive pregnant women at Ladoke Akintola University of Technology (LAUTECH) Teaching Hospital, Osogbo, Nigeria. The study protocol was reviewed and approved by our Institutional Ethical Review Committee and all participants gave their consent. The fasting serum of recruited patients were analysed for Malondialdehyde (MDA) with rapid, sensitive and specific Thiobarbituric Acid (TBA) assay, while the Total Antioxidant status (TAS) was determined using the capacity of the biological fluids to inhibit the production of thiobarbituric acid reactive substances (TBARS) from sodium benzoate under the influence of the free oxygen radicals derived from Fenton's reaction. Results: The mean serum MDA was significantly higher in the preeclamptic group ( $2.96 \mathrm{nmol} /$ $\mathrm{mL})$ than the value recorded $(1.23 \mathrm{nmol} / \mathrm{mL})$ in the control group $(\mathrm{P}=0.0001)$. Conversely, significantly lower mean TAS $(0.46 \mathrm{nmol} / \mathrm{mL}$ vs $0.62 \mathrm{nmol} / \mathrm{mL})$ was noticed in the preeclamptic group $(\mathrm{P}=0.0001)$. Conclusion: The study showed significant increase in lipid peroxidation and failure of compensatory antioxidant functions in preeclamptic pregnant Nigerian women.
\end{abstract}

Keywords: Lipid Peroxidation; Anti-Oxidant Status; Preeclampsia; Malondialdehyde

\section{Introduction}

Preeclampsia is a multisystem disorder of pregnancy, characterised by hypertension and proteinuria, usually occurring from 20th week of gestation [1]. It is a leading cause of maternal and perinatal morbidity/mortality, affecting $2 \%-3 \%$ of pregnancies and accounts for about 60,000 deaths worldwide. The impact of this disease is felt more severely in developing countries [2,3], where medical interventions may be ineffective due to late presentation of cases [4-6]. In Nigeria, preeclampsia preva-

\footnotetext{
"Financial disclosure: We declare that no funding/grant was received for this study and no conflict of interest or commercial relationship. Conflict of interest: We declare that we have no conflict of interest; no funding/grant was received for this study and no commercial relationship.

${ }^{\#}$ Corresponding author.
}

lence of $5.6 \%$ has been reported [7]

The problem of preeclampsia is also further confounded by the continued mystery of its aetiology and the unpredictable nature of the disease [8]. The pathogenesis of preeclampsia is very complex, the mechanisms that finally trigger the disease is still not clearly elucidated. However, the oxidative stress theory in preeclampsia has enjoyed great attention of Researchers [9-11]. Oxidative stress is a general term used to describe the steady state level of oxidative damage to cell, tissue or organ, caused by the reactive oxygen species (ROS) [12].

Lipid peroxidation, formation of free radicals and reactive oxygen species are normal occurrences in pregnancy, but these happen at low level in normal pregnancy, with its peak in the second trimester of pregnancy. In normal pregnancy, the balance between lipid peroxida- 
tions, free radicals (prooxidants)and the antioxidants formation are well maintained in order to minimize cellular damage $[13,14]$. When the balance is disrupted towards an overabundance of ROS, oxidative stress occurs.

In preeclampsia, oxidative stress is believed to result from increased formation of lipid peroxides, reactive oxygen speciesand superoxide anion radicals, leading to an imbalance in production between prooxidant and antioxidant defences. Theseconsequently result in endothelial dysfunction, platelet and neutrophil activation, with altered lipid synthesis towards a decrease in prostaglandin 1 and thromboxane A2 ratio $[15,16]$. The resulting imbalance in prostaglandin cascade, leads to enhanced multisystemic vasospasmic phenomenon in the kidneys, brain, uterus and placenta vessels [17].

In Nigeria, published information about the serum lipid peroxides and antioxidants status in preeclamptic women in our environment is scarce. For this reason, this study has been undertaken to establish by comparison, the serum malondialdehyde (MDA) and Total antioxidant status in women with preeclampsia and normal pregnancy in our environment.

\section{Materials \& Methods}

This was a cross sectional, case control study of pregnant patients at Ladoke Akintola University of Technology (LAUTECH) Teaching Hospital, Osogbo, Nigeria. The study was over a 3-year period (2007-2010) and the study protocol was reviewed and approved by our Institutional Ethical Review Committee. All participants gave informed consent to participate in the study.

Criteria for the diagnosis of preeclampsia and inclusion in the study were elevated blood pressure of $\geq$ 140/90 mmHg, (on two consecutive occasions taken 4 - 6 hours apart), occurring in previously normotensive pregnant women, or a rise in the baseline blood pressure of $30 \mathrm{mmHg}$ systolic or $15 \mathrm{mmHg}$ diastolic pressure, at estimated gestational age of 20 weeks and above, with associated proteinuria $(\geq 1+$ on dipstick or $\geq 300 \mathrm{mg} / 24$ hour urine collection).

The exclusion criteria were women with obesity, chronic hypertension, haemoglobinopathy, diabetes mellitus, dyslipidaemia, multiple pregnancy, liver diseases, history of use of antioxidant medications and patient's refusal of consent to participate in the study.

A total of 300 pregnant women-100 preeclamptic \& 200 normotensive controls - were recruited for the study. Each recruited preeclamptic patient was matched with 2 normotensive patients, as controls, for age ( \pm 2 years), estimated gestational age ( \pm 1 week) and parity.

Ten millilitre of fasting peripheral venous blood were collected into sterile plain bottle and centrifuged at 4000 rpm for 10 minutes. The resultant serum was collected into fresh sterile, acid-washed, plain capped bottle and stored at $-20^{\circ} \mathrm{C}$ until analysis. The serum Malondialdehyde (MDA) was estimated using a rapid, sensitive and specific Thiobarbituric Acid (TBA) assay [18] and the Total Anti-oxidant Status (TAS) was determined as by Koracevic et al. [19]. In Koracevic method, a standardised solution of Fe-EDTA complex reacts with hydrogen peroxide by a Fenton-type reaction, leading to the formation of hydroxyl radicals $(\bullet \mathrm{OH})$. These reactive oxygen species degrade benzoate, resulting in the release of TBARS. Antioxidants from the added sample of human fluid cause suppression of the production of TBARS. This reaction can be measured spectrophotometrically and the inhibition of colour development defined as the anti-oxidative activity

\section{Statistics}

Data obtained was analysed with Statistical Package for Social Sciences version 16 (SPSS Inc., Chicago, IL, USA) for continuous variables as mean \pm standard deviation, Student t-test and confidence interval. Level of significance was set at $\mathrm{P} \leq 0.05$.

\section{Results}

A total of 300 patients were recruited for study, of which 100 were women diagnosed with preeclampsia and 200 were normotensive pregnant women (Controls). The women recruited as "controls" were matched at ratio of 2 for each woman with preeclampsia for age ( \pm 2 years), estimated gestational age ( \pm 1 week) and parity. There was no significant difference in the mean estimated gestational age and parity distribution at recruitment in both groups. The mean age of patients recruited in the control was higher than in the preeclamptic group, but this was statistically insignificant ( 31.2 vs $30.9 ; \mathrm{P}=0.2673)$. Whereas, parameters such as Weight, Body mass index, Systolic and Diastolic blood pressures were all extremely significantly different in the preeclamptic group than control (Table 1). However, no significant difference was noticed in the height of the patients between the groups.

In Table 2, the mean serum MDA was significantly higher in the preeclamptic group $(2.96 \pm 0.75 \mathrm{nmol} / \mathrm{mL})$ than the value recorded $(1.23 \pm 0.12 \mathrm{nmol} / \mathrm{mL})$ in the control group $(\mathrm{P}=0.0001)$. Conversely, significantly lower mean TAS of $0.46(0.09) \mathrm{nmol} / \mathrm{mL}$ was recorded in the preeclamptic group, in contrast to mean value of 0.62 $(0.13) \mathrm{nmol} / \mathrm{mL}$ in the control group $(\mathrm{P}=0.0001)$.

\section{Discussion}

The patients recruited for this study were matched for age, estimated gestational age and parity. This and other efforts on strict enrolment criteria were to eliminate the 
Table 1. Socio-demographic factors of preeclamptic women and the normotensive control.

\begin{tabular}{cccccc}
\hline Parameters & $\begin{array}{c}\text { Preeclamptic Patients } \\
\mathbf{n}=\mathbf{1 0 0} \\
\text { mean (SD) }\end{array}$ & $\begin{array}{c}\text { Control } \\
\mathbf{n}=\mathbf{2 0 0} \\
\text { mean (SD) }\end{array}$ & $\mathbf{t}$ & P-Value & C.I \\
\hline Age (Years) & $30.90(2.4)$ & $31.20(2.1)$ & 1.1113 & 0.2673 & $-0.831,-0.231$ \\
EGA (Weeks) & $28.64(6.32)$ & $28.56(6.24)$ & 0.1042 & 0.9171 & $-1.4304,1.5904$ \\
Weight $(\mathrm{kg})$ & $68.90(10.1)$ & $63.40(8.2)$ & 5.0592 & $<0.0001$ & $3.3610,7.6390$ \\
Height $(\mathrm{m})$ & $1.64(0.07)$ & $1.65(0.06)$ & 1.2859 & 0.1995 & $-0.0253,0.0053$ \\
BMI $\left(\mathrm{Kg} / \mathrm{m}^{2}\right)$ & $25.62(2.06)$ & $23.29(2.28)$ & 8.6109 & $<0.0001$ & $1.7975,2.8625$ \\
SBP $(\mathrm{mmHg})$ & $153.37(6.23)$ & $116.89(4.18)$ & 60.1004 & $<0.0001$ & $35.2855,37.6745$ \\
DBP $(\mathrm{mmHg})$ & $98.16(7.89)$ & $87.23(9.73)$ & 9.7429 & $<0.0001$ & $8.7223,13.1377$ \\
\hline
\end{tabular}

Table 2. Comparison of serum malondialdehyde \& total antioxidant status in preeclamptic women \& normotensive control.

\begin{tabular}{cccccc}
\hline Factors & $\begin{array}{c}\text { Preeclamptic Patients } \\
\mathbf{n = 1 0 0}\end{array}$ & $\begin{array}{c}\text { Control } \\
\mathbf{n = 2 0 0}\end{array}$ & t & P value & C.I \\
\hline MDA $(\mathrm{nmol} / \mathrm{mL})$ & $2.96(0.75)$ & $1.23(0.12)$ & 31.8664 & $<0.0001$ & $1.6232,1.8368$ \\
TAS $(\mathrm{nmol} / \mathrm{mL})$ & $0.46(0.09)$ & $0.62(0.13)$ & 11.0503 & $<0.0001$ & $-0.1885,-0.1315$ \\
\hline
\end{tabular}

confounding effects of these socio-demographic factors. At a prevalence of $5.6 \%$ in the population of our pregnant women and low access to adequate obstetric care, due to poverty and ignorance $[7,20]$ preeclampsia/eclampsia has remained one of the greatest five major contributors towards the poor maternal/perinatal morbidity/mortality in our population $[3,5,6]$.

The findings from this study showed evidence of increased lipid peroxidation and reduced levels of total antioxidant status in preeclamptic women in our population. These are consistent with the conclusions from studies in other populations beyond Nigeria [21-24], though some other studies had reported no significant difference in the levels of lipid peroxidation between gestational age-matched cases and controls [25-27]. However, striking patterns noticed in our study are relatively lower MDA (prooxidant) levels in our patients, both in the preeclampticand normotensive control groups. From our study, the mean MDA in the preeclamptic and normotensive pregnant controls were $2.96 \mathrm{nmol} / \mathrm{ml}$ and $1.23 \mathrm{nmol} /$ $\mathrm{ml}$ respectively. These values are much lower than the reports from other regions of the world, as reported by Howlader et al. [28] and Begum [29]. Our findings are similar to that of Nnodim et al. [30] in South-east Nigeria population. They had reported values of 3.91 and 1.68 nmol respectively in their patients at Owerri, Nigeria. Whether this is due to genetic adaptive abilities or nutrition cannot be established from this study. It might however be an interesting focus of future studies.

In this study, in other to eliminate some confounding factors, patients in either arm of study on antioxidant medications and body mass index of greater or equal to 30
$\mathrm{Kg} / \mathrm{m}^{2}$ or hyperlipidaemia were excluded. Permissible medications were limited only to ferrous sulphate and folic acid tablet $200 \mathrm{mg}$ twice daily and $5 \mathrm{mg}$ daily respectively. The significant difference in the BMI between the groups could only be accounted for by the difference of the mean weights between the groups, the mean heights between the groups being statistically insignificant. Oedema is a well-known finding in preeclampsia and might have accounted for the difference in the BMI. Other possible factors such as muscle mass and body fat were not addressed in the study.

The TAS was remarkably more reduced in the preeclamptic group by MDA/TAS factor of greater than six (2.96/0.46) when compared to about factors of two (1.23/ 0.63 ) in normotensive pregnant controls. This demonstrated increased lipid peroxidation in conjunction with poor antioxidant protective/compensatory adaptation in preeclampsia and buttressed the possible effect of oxidative stress theory in preeclampsia in our population. Though, it may therefore be reasoned that addition of supplemental antioxidant nutrients, such as vitamins $\mathrm{C}, \mathrm{E}$, carotenoids, selenium and others may be beneficial in improving the TAS status in all patients. Present weight of opinions did not suggest clinical benefits of such interventions [31,32]. However, further researches in this aspect may be justified.

\section{Conclusion}

This study demonstrated significant increase in lipid membrane damage activities (lipid peroxidation), as evidenced by rise of serum MDA in preeclamptic women 
and failure of compensatory antioxidant functions demonstrated by overall lower antioxidant capacity in preeclamptic pregnant women. These further buttress a possible link between oxidative stress and preeclampsia. Further researches on possible effects of antioxidant supplements may be justified.

\section{Acknowledgements}

We are grateful to all our patients who consented to participate in this study and all our resident Doctors that assisted in the conduct of the study.

\section{REFERENCES}

[1] ACOG Technical Bulletin, "Management of Preeclampsia," No. 91, Committee on Technical Bulletins of the American College of Obstetricians and Gynecologists, Washington DC, 1986.

[2] G. Igberase and P. Ebeigbe, "Eclampsia: Ten-Year of Experience in a Rural Tertiary Hospital in the Niger Delta, Nigeria," Journal of Obstetrics \& Gynecology, Vol. 26, No. 5, 2006, pp. 414-417. doi:10.1080/01443610600720113

[3] Y. M. Adamu, H. M. Salihu, N. Sathiakumar and G. R. Alexander, "Maternal Mortality in Northern Nigeria: A Population-Based Study," European Journal of Obstetrics \& Gynecology and Reproductive Biology, Vol. 109, No. 2, 2003, pp. 153-159. doi:10.1016/S0301-2115(03)00009-5.

[4] J. I. Ikechebelu and C. C. Okoli, "Review of Eclampsia at the Nnamdi Azikiwe University Teaching Hospital, Nnewi (January 1996-December 2000)," Journal of Obstetrics \& Gynecology, Vol. 22, No. 3, 2002, pp. 287-290. doi: 10.1080/01443610220130580

[5] S. O. Onuh and A. O. Aisien, "Maternal and Fetal Outcome in Eclamptic Patients in Benin City, Nigeria," Journal of Obstetrics \& Gynecology, Vol. 24, No. 7, 2004, pp. 765-768. doi:10.1080/01443610400009451

[6] J. U. E. Onakewhor and E. P. Gharoro, "Changing Trends in Maternal Mortality in a Developing Country," Nigerian Journal of Clinical Practice, Vol. 11, No. 2, 2008, pp. 111-120.

[7] A. N. Onyiriuka and A. AOkolo, "Perinatal Outcome in Patients with Pre-Eclampsia in Benin City, Nigeria," Tropical Journal of Obstetrics and Gynaecology, Vol. 21, No. 2, 2004, pp. 148-152.

[8] L. Duley, "Pre-Eclampsia and the Hypertensive Disorders of Pregnancy," British Medical Bulletin, Vol. 67, No. 1, 2003, pp. 161-176. doi:10.1093/bmb/ldg005

[9] C. A. Hubel, "Dyslipidemia, Iron, and Oxidative Stress in Preeclampsia: Assessment of Maternal and Feto-Placental Interactions," Seminars in Reproductive Endocrinology, Vol. 16, No. 1, 1998, pp. 75-92. doi:10.1055/s-2007-1016255

[10] H. Laivuori, R. Kaaja, U. Turpeinen, L. Viinikka and O. Ylikorkala, "Plasma Homocysteine Levels Elevated and
Inversely Related to Insulin Sensitivity in Preeclampsia," Obstetrics and Gynaecology, Vol. 93, No. 4, 1999, pp. 489-493. doi:10.1016/S0029-7844(98)00527-4.

[11] G. P. Sacks, K. Studena, K. Sargent and C. W. Redman, "Normal Pregnancy and Preeclampsia Both Produce Inflammatory Changes in Peripheral Blood Leukocytes Akin to Those of Sepsis," American Journal of Obstetrics \& Gynecology, Vol. 179, No. 1, 1998, pp. 80-86. doi:10.1016/S0002-9378(98)70254-6.

[12] Oxidative Stress, Wikipedia Foundation Inc., 2013. http://en.wikipedia.org/wiki/Oxidative_stress

[13] D. Wickens, M. H. Wilikins, J. Lunce, G. Ball and T. L. Dormandy, "Free Radical Oxidation Products in Normal and Abnormal Pregnancy," Annals of Clinical Biochemistry, Vol. 18, No. 3, 1998, pp. 158-162.

[14] A. K. Poranen, U. Ekblad, P. Uotila and M. Ahotupa, "Lipid Peroxidation and Antioxidants in Normal and Preeclamptic Pregnancies," Placenta, Vol. 17, 1996, pp. 401405. doi:10.1016/S0143-4004(96)90021-1.

[15] J. M. Roberts, R. N. Taylor, T. J. Musci, G. M. Rodgers, C. A. Hubel and M. K. Mclaughlin, "Pre-Eclampsia: An Endothelial Cell Disorder," American Journal of Obstetrics \& Gynecology, Vol. 161, No. 5, 1989, pp. 12001204.

[16] J. M. Roberts and C. A. Hubel, "Oxidative Stress in Preeclampsia," American Journal of Obstetrics \& Gynecology, Vol. 190, No. 5, 2004, pp. 1177-1178. doi:10.1016/j.ajog.2004.04.001

[17] A. Barden, J. Ritchie, B. Walters, C. Michael, J. Rivera, T. Mori, K. Croft and L. Beilin, "Study of Plasma Factors Associated with Neutrophil Activation and Lipid Peroxidation in Preeclampsia," Hypertension, Vol. 38, No. 4, 2001, pp. 8003-8008. doi:10.1161/hy1101.092969.

[18] N. A. Botsuglou, "Rapid, Sensitive and Specific Thiobarbituric Acid Method for Measuring Lipid Peroxidation in Animal Tissue Food and Feedstuff Samples," Journal of Agricultural and Food Chemistry, Vol. 42, No. 9, 1994, pp. 1993-1997.

[19] D. Koracevic, G. Koracevic, V. Djordjevic, S. Andrejevic and V. Cosic, "Method for the Measurement of Antioxidant Activity in Human Fluids," Journal of Clinical Pathology, Vol. 54, No. 5, 2001, pp. 356-361. doi:10.1136/jep.54.5.356.

[20] K. O. Osungbade and O. K. Ige, "Public Health Perspectives of Preeclampsia in Developing Countries: Implication for Health System Strengthening," Journal of Pregnancy, Vol. 2011, 2011, Article ID: 481095.

[21] G. Bayhan, Y. Atamer, A. Atamer, et al., "Significance of Changes in Lipid Peroxides and Antioxidant Enzyme Activities in Pregnant Women with Preeclampsia and Eclampsia," Clinical \& Experimental Obstetrics \& Gynecology, Vol. 27, 2000, pp. 142-146.

[22] E. M. El-Salahy, M. I. Ahmed, A. El-Gharieb, et al., "New Scope in Angiogenesis: Role of Vascular Endothelial Growth Factor (VEGF), NO, Lipid Peroxidation, and Vitamin E in the Pathophysiology of Pre-Eclampsia among Egyptian Females," Clinical Biochemistry, Vol. 
34, No. 4, 2001, pp. 323-329.

doi:10.1016/S0009-9120(01)00230-2.

[23] J. Kornacki, J. Kozlik, M. Dubiel, et al., "Estimation of Oxidative Stress and Its Correlation with Uterine Arteries Doppler Velocimetry in Women with Preeclampsia," Ginekologia Polska, Vol. 75, 2004, pp. 681-691 (in Polish).

[24] Y. Atamer, Y. Kocyigit, B. Yokus, et al., "Lipid Peroxidation, Antioxidant Defense, Status of Trace Metals and Leptin Levels in Preeclampsia," European Journal of Obstetrics \& Gynecology and Reproductive Biology, Vol. 119, No. 1, 2005, pp. 60-66. doi:10.1016/j.ejogrb.2004.06.033

[25] R. S. Bowen, J. Moodley, M. F. Dutton, et al., "Oxidative Stress in Pre-Eclampsia," Acta Obstetricia et Gynecologica Scandinavica, Vol. 80, No. 8, 2001, pp. 719-725. doi:10.1034/j.1600-0412.2001.080008719.x

[26] F. Diedrich, A. Renner, W. Rath, et al., "Lipid Hydroperoxides and Free Radical Scavenging Enzyme Activities in Preeclampsia and HELLP (Hemolysis, Elevated Liver Enzymes, and Low Platelet Count) Syndrome: No Evidence for Circulating Primary Products of Lipid Peroxidation," American Journal of Obstetrics \& Gynecology, Vol. 185, No. 1, 2001, pp. 166-172. doi: $10.1067 / \mathrm{mob} .2001 .115281$

[27] M. T. Raijmakers, B. J. van Tits, H. L. Hak-Lemmers, et al., "Low Plasma Levels of Oxidized Low Density Lipoprotein in Preeclampsia," Acta Obstetricia et Gynecologica Scandinavica, Vol. 93, 2004, pp. 1173-1177. doi:10.1080/j.0001-6349.2004.00539.x

[28] Z. H. Howlader, Y. Kabir, T. A. Khan, R. Islam, F. Begum and F. G. Huffman, "Plasma Lipid Profile, Lipid Peroxidation and Antioxidant Status in Preeclamptic and Uncomplicated Pregnancies in Bangladesh," Journal of Medical Sciences, Vol. 7, No. 8, 2007, pp. 1276-1282. doi:10.3923/jms.2007.1276.1282.

[29] R. Begum, "Lipid Peroxidation and Antioxidant Status in Preeclampsia," Journal of Enam Medical College, Vol. 1, No. 2, 2011, pp. 56-59.

[30] J. Nnodim, A. Ihim and H. I. Uduji, "Alterations in Antioxidants Enzymes and Malondialdehyde Status in Preeclampsia," Asian Pacific Journal of Tropical Biomedicine, 2012, pp. S750-S752.

[31] J. A. Spinnato 2nd, S. Freire, E. Pinto, J. L. Silva, et al., "Antioxidant Therapy to Prevent Preeclampsia: A Randomized Controlled Trial," Obstetrics \& Gynecology, Vol. 110, No. 6, 2007, pp. 1311-1318.

[32] M. Boulvain, "Antioxidants for Preventing Preeclampsia: RHL Commentary," The WHO Reproductive Library, World Health Organisation, Geneva, 2008. 